\title{
Improving value and access to specialty medical care for families: a pediatric surgery telehealth program
}

\author{
Paige Dean, BSc \\ Maureen O'Donnell, MD \\ Lenny Zhou, MMOR \\ Erik D. Skarsgard, MD
}

Accepted Mar. 8, 2019

\author{
Correspondence to: \\ E.D. Skarsgard \\ Rm. K0-110 Ambulatory Care Building \\ 4480 Oak St \\ Vancouver BC V6H 3V4 \\ eskarsgard@cw.bc.ca
}

DOI: $10.1503 /$ cjs.005918
Background: In Canada, access to subspecialty surgical services for children imposes inconvenience and financial hardship on geographically remote families. The purpose of this study was to evaluate a recently implemented pediatric surgical telehealth pilot program from the family and provider perspectives.

Methods: Enabled by an existing telehealth infrastructure for pediatric subspecialty medicine and mental health, a pilot telehealth program for surgical consultation was established by a single surgeon in British Columbia. Following establishment of eligibility criteria, patients from remote communities requiring new consultation or clinical follow-up were offered a telehealth alternative. At the end of the encounter, both the parent and patient (if appropriate) provided feedback via a questionnaire. Provider satisfaction was also assessed via a questionnaire. We estimated costs avoided and analyzed data on pediatric surgery consultation wait time.

Results: Between September 2014 and November 2017, 80 patients were seen in 19 remote telehealth centres, 23 as new referrals and 57 in follow-up consultation. Among new referrals, the commonest diagnosis was chest wall deformity. The average travel distance avoided was $705 \mathrm{~km}$, with an estimated direct cost avoidance of $\$ 585$. Sixty-four families (80\%) completed the questionnaire. Almost all (63 [98\%]) indicated high overall satisfaction with the telehealth experience. Provider satisfaction was similarly high, in terms of both the technology user interface and clinical effectiveness. Overall pediatric surgical consultation wait times were unaffected.

Conclusion: Implementation of telehealth technology in a pediatric surgical practice offered high value to patients/families and, from the provider's perspective, yielded an acceptable alternative to in-person assessment.

Contexte : Au Canada, l'accès aux services chirurgicaux surspécialisés pour enfants est source d'inconvénients et de difficultés financières pour les familles vivant en région éloignée. L'objectif de cette étude était d'évaluer le point de vue des familles et des fournisseurs de services sur un programme pilote de télésanté pédiatrique récemment mis en œuvre.

Méthodes : Ce programme pilote de consultation chirurgicale à distance a été mis sur pied par un chirurgien de Colombie-Britannique, qui s'est servi d'une infrastructure de télésanté préexistante permettant la prestation de services surspécialisés de médecine et de santé mentale pour enfants. Une fois leur admissibilité établie, les patients vivant en région éloignée et ayant besoin d'une consultation ou d'un suivi clinique se sont vu offrir des services de télésanté. Après la consultation, les parents et le patient (lorsque c'était approprié) ont rempli un formulaire de rétroaction. La satisfaction des fournisseurs de soins a été également évaluée au moyen d'un questionnaire. Nous avons estimé les coûts évités et analysé les données sur le temps d'attente pour une consultation en chirurgie pédiatrique.

Résultats : Entre septembre 2014 et novembre 2017, 80 patients ont consulté 19 centres de télésanté : 23 pour une nouvelle consultation et 57 pour un suivi. Parmi les nouveaux cas, le diagnostic le plus fréquent était une malformation de la paroi thoracique. En moyenne, $705 \mathrm{~km}$ de déplacements ont été évités, ce qui représente un coût estimé de 585 \$. Soixante-quatre familles $(80 \%)$ ont rempli le questionnaire, et presque toutes (63 [98\%]) se sont dites globalement satisfaites de leur expérience de télésanté. La satisfaction des fournisseurs de soins était également élevée, tant en ce qui a trait à l'interface utilisateur des outils technologiques qu'à l'efficacité clinique. Le programme n'a eu aucun effet sur le temps d'attente général pour une consultation en chirurgie pédiatrique.

Conclusion : L'utilisation de services de télésanté en chirurgie pédiatrique a été d'une grande valeur pour les patients et leur famille. Du point de vue des fournisseurs de soins, elle a constitué une solution de rechange acceptable aux consultations en personne. 
$\mathrm{T}$ elehealth is the delivery of health care services across geographical barriers using information and communication technologies with the intent of improving the health outcomes of patients and their communities. ${ }^{1}$ Rapid advances in the availability and use of information and communication technologies, coincident with reduction in cost, have created a niche for telehealth as a viable alternative to the traditional in-person encounter in selected cases and an intentional strategy within models of delivery of health care services delivery. The integration of telehealth into delivery of health care services offers benefits to patients, who are spared the time and expense associated with travel to be seen in person. Furthermore, it has the potential to substantially benefit a health care system of limited capacity by reducing the demand for in-person clinical evaluation. Telehealth applications are particularly suited to large geographical areas with sparse, frequently underserved populations like Canada, where rural residents travel an average of $60 \mathrm{~km}$ (up to $300 \mathrm{~km}$ in northern communities) just to visit a family doctor. $^{2,3}$

British Columbia is a province with areas of both high and low population density, a characteristic that is common across the Canadian provinces. ${ }^{4}$ In British Columbia in particular, people residing in the expanse beyond the southwest region, which is well populated, have historically had more difficulty accessing specialty and subspecialty medical care. ${ }^{5,6}$ Child-specific health care services in the north are provided by generalists in only 1 regional centre (Prince George, with no capacity in subspecialty pediatrics. Elsewhere, there are pockets of pediatric subspecialty capacity; however, tertiary/quaternary surgical services for children are available only at the children's hospital in Vancouver.

In a unique and specifically designed collaboration, Child Health BC, a provincial network, established the Technology Enabled Access to Care for Children initiative, which facilitates relationships between technology leaders in health authorities and clinical leaders at BC Children's Hospital. Leveraging existing partnerships with the 5 regional health authorities and using historical data on use of child health care services from the Canadian Institute for Health Information to identify the optimal location of remote site "nodes," the Technology Enabled Access to Care for Children program has made strategic investment in information and communication technologies, nursing and clerical infrastructure to create a provincial telehealth network to allow access to pediatric subspecialty consultation for children and families across the province. The network consists of geographically distributed secure videoconferencing facilities with clerical, nursing and information technology support. Although the province has had functioning telehealth programs in mental health and subspecialty pediatrics for some time, there has been no experience with telehealth in pediatric surgery. The objective of this pilot project was to explore the patient/provider experience with telehealth in the context of pediatric surgery and to evaluate the impact of a telehealth alternative on overall access to pediatric surgical consultation.

\section{Methods}

A single pediatric surgeon (E.D.S.) established a consultative surgical telehealth practice based at BC Children's Hospital, Vancouver. Telehealth access to remote sites was facilitated by a dedicated desktop personal video system (Cisco Telepresence System EX90, Cisco Systems) in the surgeon's office, which allowed secure video connection and sharing of document images (drawings, photographs and radiographs) with remote sites, and gave the surgeon control of the remote site's camera.

Case selection for consultation was initially limited to follow-up for patients from remote communities who had undergone surgical procedures at BC Children's Hospital. However, as experience increased, consultation was offered increasingly for new patient referrals. A triage and caseselection process for new referrals was established. If a request for consultation from a "remote community" (arbitrarily designated as being more than $250 \mathrm{~km}$ from Vancouver on the BC mainland, or anywhere on Vancouver Island) seemed appropriate for telehealth, a form was sent to the referring physician to see whether this would be appropriate for the family and also to organize locally any laboratory or radiologic testing that might be required in advance of the consultation. At the outset, consultations were restricted to postoperative follow-up consultations or new patient referrals in which it was assumed that a major element of the consultation would be patient and family education (e.g., a first assessment of a chest wall deformity). A consultation was then arranged at the telehealth centre closest to the family's home.

Many, though not all, of the remote sites were "pediatric-enhanced" sites that delivered telehealth but also offered a clinic nurse, who obtained weight and vital sign measurements before the start of the appointment. Appointments were initially scheduled at 45 -minute intervals, with 15 minutes between appointments; however, later in the experience, some appointments were scheduled at 30-minute intervals.

At the end of the encounter, both the parent and patient (if appropriate) provided feedback via a questionnaire, which included an option for narrative comments (Appendix 1, available at canjsurg.ca/005919-a1). Satisfaction of the provider (telehealth provider and telehealth support staff) was also assessed by way of a questionnaire.

\section{Data analysis}

We analyzed patient demographic characteristics (including diagnosis and home postal code) to estimate 
cost avoidance associated with the telehealth consultation. An assumption was made that families living more than $600 \mathrm{~km}$ from the hospital would travel to Vancouver by airplane for an appointment. For these patients, we calculated costs based on having 2 people travel by airplane to Vancouver and stay in a hotel for 1 night. Air travel costs used were actual economy airfares to Vancouver from airports closest to the patient's home. We assumed that those living $600 \mathrm{~km}$ or less away would drive to Vancouver, and we calculated an average trip length for this group. Estimated fuel costs were based on gasoline costs in Vancouver in July 2016 (\$1.16 per litre), the travel distance to Vancouver and an assumed fuel efficiency of a mid-sized car travelling by highway $(11 \mathrm{~L} / 100 \mathrm{~km})$. It was assumed that patients living $300-600 \mathrm{~km}$ away would arrive the night before, so the cost of 1 night's accommodation (\$225, based on an average cost of hotels within a $16-\mathrm{km}$ radius of the hospital) was added to the expense estimate. All cost estimates included a $\$ 50$ per diem expense for meals.

We analyzed pediatric surgery consultation Wait 1 (the time from referral to consultation) data before and after telehealth implementation to determine whether integration of a telehealth alternative to in-person consultation had a beneficial impact on overall access.

\section{Ethics approval}

As this was a quality-improvement study, ethics approval was not obtained.

\section{Results}

Between September 2014 and November 2017, 80 patients were offered consultation by telehealth. Of these, 23 were new patient referrals and 57 were follow-up consultations. The reasons/diagnoses for the completed consultations are summarized in Table 1.

The average age of the patients was 7 years (range 1 mo-21 yr). All patients were accompanied by at least 1 family member at their telehealth visit.

The locations of the telehealth support sites are displayed in Fig. 1. The average distance from BC Children's Hospital was 705 (range 89-2400) km. The most frequently accessed telehealth location was in Kelowna (28 cases), which is located $390 \mathrm{~km}$ from BC Children's Hospital. The estimated cost savings averaged $\$ 585$ (Table 2).

Sixty-four patients (80\%) completed the patient/family questionnaire. Fifty-four families (84\%) reported that this was their first encounter with telehealth. Families reported experiencing savings in travel time, school time missed and parental work time missed: without telehealth, families would have experienced an additional
5.35 hours of travel (1 way), 1 missed day of school for the child and 1 missed day of work for 1 parent or both

\begin{tabular}{|c|c|}
\hline Type of consultation & No. of patients \\
\hline \multicolumn{2}{|l|}{ New referral $(n=23)$} \\
\hline Pectus carinatum/excavatum & 11 \\
\hline Umbilical/epigastric hernia & 3 \\
\hline Morgagni hernia & 2 \\
\hline Diastasis recti & 1 \\
\hline Hirschsprung disease & 1 \\
\hline Inguinal hernia/hydrocele & 1 \\
\hline Other & 4 \\
\hline \multicolumn{2}{|l|}{ Follow-up $(n=57)$} \\
\hline Pectus carinatum/excavatum & 14 \\
\hline Bowel obstruction/perforation/resection & 11 \\
\hline Appendectomy & 4 \\
\hline Anorectal malformation & 3 \\
\hline Congenital diaphragmatic hernia & 2 \\
\hline Congenital pulmonary airway malformation & 2 \\
\hline Rectal prolapse & 2 \\
\hline Esophageal atresia & 1 \\
\hline Hirschsprung disease & 1 \\
\hline Hydrocele repair & 1 \\
\hline Morgagni hernia & 1 \\
\hline Other & 15 \\
\hline
\end{tabular}

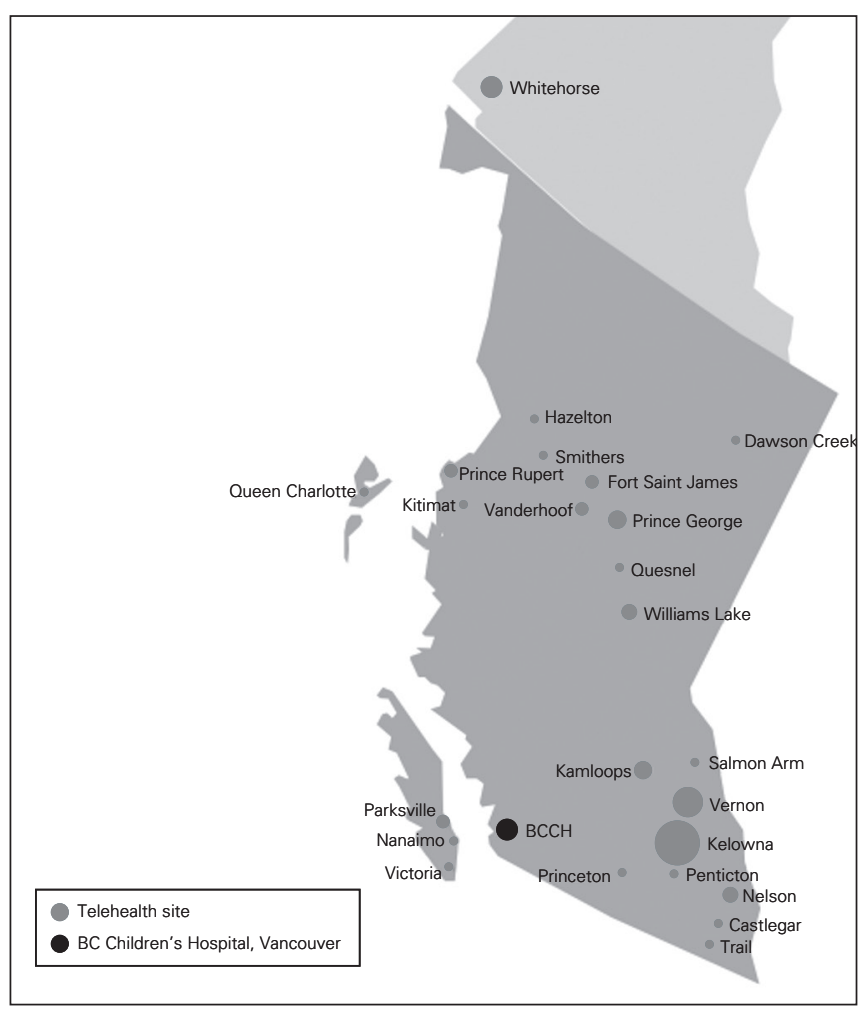

Fig. 1. Map of British Columbia indicating telehealth sites (closed circles). Size of circle is proportional to the number of patients seen from that site. 


\begin{tabular}{|c|c|}
\hline Potential expense & Cost estimate, $\$^{*}$ \\
\hline \multicolumn{2}{|l|}{ Distance $>600 \mathrm{~km}(n=29)$} \\
\hline Round-trip airfare & 300/person \\
\hline Accommodation in Vancouver (1 night) & 225 \\
\hline Per diem expenses & 50/person \\
\hline Total for 2 travellers & 925 \\
\hline \multicolumn{2}{|l|}{ Distance $\leq 600 \mathrm{~km}(n=51)$} \\
\hline \multicolumn{2}{|l|}{ Day trip (distance $\leq 300 \mathrm{~km})(n=6)$} \\
\hline Average fuel cost in Vancouver & 1.16/L \\
\hline Average fuel efficiency & $11 \mathrm{~L} / 100 \mathrm{~km}$ \\
\hline Per diem expenses & 50/person \\
\hline Total for 2 travellers ${ }^{\dagger}$ & 149 \\
\hline \multicolumn{2}{|l|}{ Overnight trip (distance $>300 \mathrm{~km})(n=45)$} \\
\hline Average fuel cost in Vancouver & $1.16 / \mathrm{L}$ \\
\hline Average fuel efficiency & $11 \mathrm{~L} / 100 \mathrm{~km}$ \\
\hline Accommodation in Vancouver (1 night) & 225 \\
\hline Per diem expenses & 50/person \\
\hline Total for 2 travellers $\dagger$ & 424 \\
\hline
\end{tabular}

parents (34 cases [42\%]) (Fig. 2). Sixty-three families $(98 \%)$ indicated that they would use telehealth again. All patients/families indicated that they could see and hear the doctor clearly for all or most of the telehealth visit, and $63(98 \%)$ felt that the doctor could see and hear them clearly throughout the visit. Sixty-three families (98\%) reported feeling comfortable in the room where the telehealth visit was held.

From the provider's perspective, the telehealth experience was very positive. There was 1 instance of a delay from a dropped connection. The remote site camera was easy to control. There were no patients in whom a clinical assessment was impossible. Patient education was enhanced by the use of a digital whiteboard for illustrations and by the ability to share $\mathrm{x}$-ray films with the remote site. High-fidelity visual wound assessment was easily achieved. The availability of a telehealth alternative did not reduce aggregate wait times for consultation, although the telehealth encounters represented a small proportion of the provider's total ambulatory visits $(>700)$ during the study period.
A

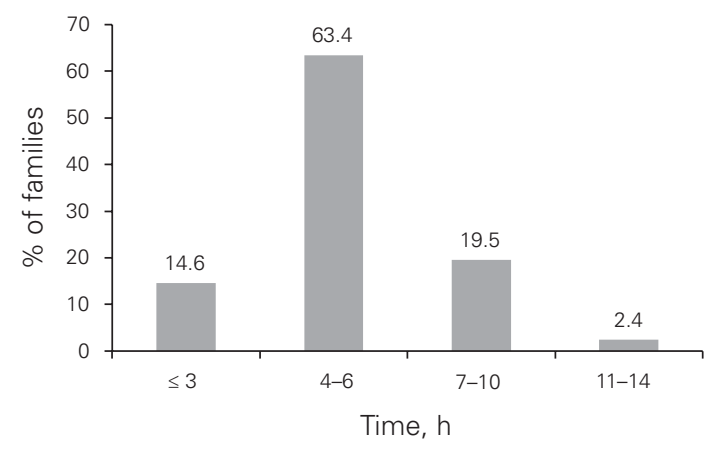

C

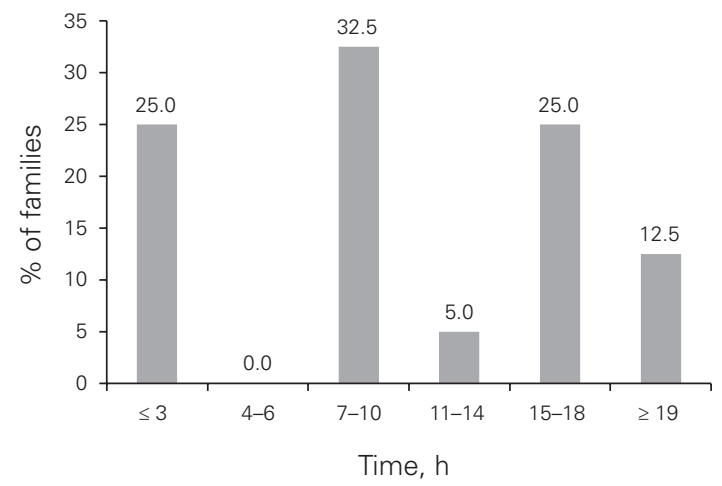

B

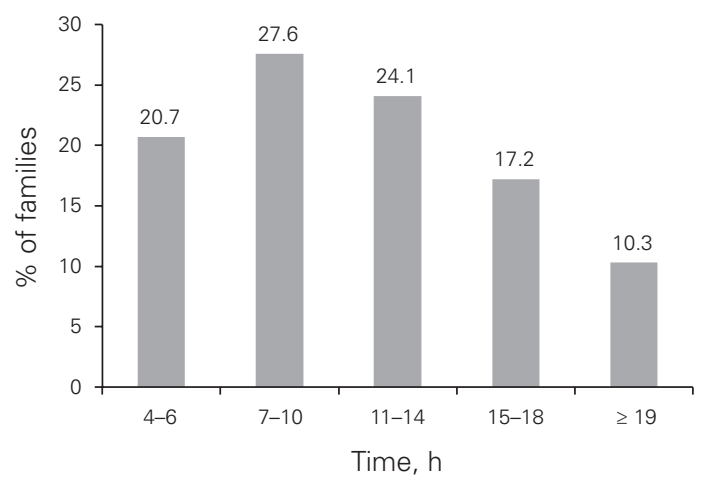

D

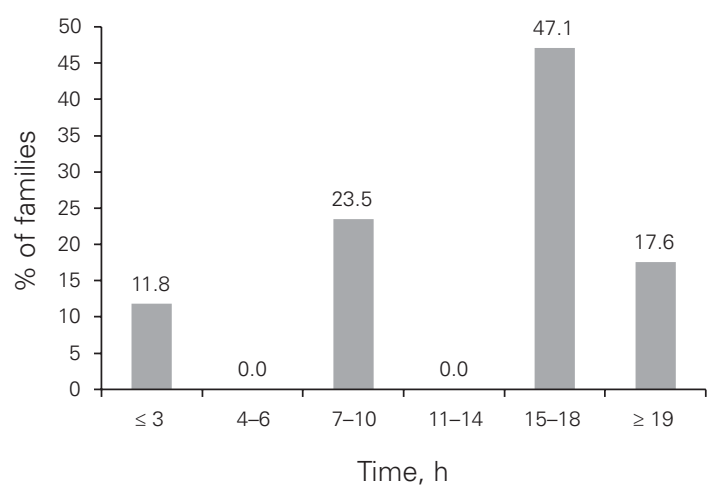

Fig. 2. Estimated savings in travel time (1 direction) (A), absence from school (B), missed time from work for 1 parent (C) and missed time from work for both parents (D) with telehealth. 


\section{Discussion}

Setting up a telehealth program for children's surgery requires consideration of the types of patients who can be reasonably assessed by videoconferencing. Initially, evaluation was limited to patients from remote sites, who had undergone surgery for which surgical follow-up was necessary. This assumed that the availability of vital signs and weight, combined with a history and general evaluation of the surgical site (without the need to specifically palpate or auscultate) would be enough to support an accurate clinical assessment. Having a nurse in the room at the remote site was particularly helpful and assisted in the clinical evaluation (i.e., patient positioning relative to the remote site camera, validation of remote visual observations, palpation to evaluate abdominal distension and absence of tenderness). The availability of an electronic whiteboard for illustrations and the ability to share radiologic images with the remote site further facilitated the transfer of information during the encounter.

When we began to see new referrals, we started with diagnoses for which a key focus of the clinical encounter would be on patient and family education, and discussion of the options for care. The surgeon involved receives the majority of provincial referrals for chest wall deformities in children and found that a videoconferencing format was well suited to the needs of this patient group. Understanding the nuances of the deformity required the use of light shadowing and positioning to appreciate both severity and degree of asymmetry, and any limitation of evaluation was more than offset by the ability to provide information on the natural history of the condition and options for treatment. It was felt, however, that a decision for surgery could safely be made only following an in-person assessment. Other types of new patient consultations that were reasonably amenable to virtual assessment were those that relied on the history (such as a pediatrician referral of a toddler with constipation, in whom Hirschsprung disease was suspected) or physical findings that required visualization more than palpation to make a diagnosis (e.g., inguinal hernia, diastasis recti). For the patient with possible Hirschsprung disease, the quality of the history obtained and, notably, the absence of hallmark findings (chronic abdominal distension and failure to thrive) led to the conclusion that the diagnosis was sufficiently unlikely that the family could be spared a trip to Vancouver for a diagnostic biopsy procedure.

An important finding of our study was the perceived value of telehealth to patients and families. In nearly every instance, families felt that the encounter met their expectations, and even in situations in which it was agreed that an in-person consultation would be necessary to make a final decision for treatment, families still identified value in the telehealth encounter. Questionnaire respondents felt that telehealth was "an excellent service and an ingenious way to connect, ask questions and learn" (respondent 1). The availability of telehealth was described as "an extremely valuable experience and valuable tool" (respondent 2 ), and 1 respondent (respondent 3 ) commented "hope that it is one that will be a continued practice."

Telehealth presents obvious economic benefit to families. The cost avoidance was estimated to be $\$ 585$ on average, which included only the direct expenses associated with travel to Vancouver. This was higher than the estimated average travel cost of $\$ 174$ in a 2002 pediatric surgical telehealth study from Saskatchewan, in which different costing methods from ours were used. ${ }^{7}$ In a 2015 study from Toronto, $30 \%$ of families rated their out-of-pocket expenses associated with travel to the children's hospital for pediatric surgical consultation as somewhat high or high. ${ }^{8}$ The travel cost savings, as well as the reduced school absenteeism for school-age patients and avoidance of potential lost parental wages, all contribute to the value of telehealth from the patient/family perspective.

From the provider's perspective, remote consultation by telehealth was a very effective complement to in-person consultation. The communication interface was easy to master, and the ability to control the remote camera and make use of interactive technologies for enhanced education and communication (e.g., a whiteboard for illustrations) allowed for an encounter that simulates what occurs in person. Incorporating an experienced nurse at the remote site substantially increased the fidelity of clinical evaluation. In addition, the ability to schedule several appointments consecutively from multiple sites across the province simulated the workflow of an in-person clinic, where one goes from one room to the next to see consecutive patients. One obvious difference between the 2 workflows is that, in the virtual instance, the provider cannot run late and cannot see a waiting patient earlier than the scheduled time. The 45 minutes scheduled for telehealth appointments is longer than what is scheduled for inperson visits, which is usually 30 minutes for new referrals and 15 minutes for noncomplex patient follow-up visits. On the other hand, having a few minutes between the end of one virtual appointment and the beginning of the next allows time for dictation and organization of any required follow-up or diagnostic testing, which often gets deferred until the end of an in-person clinic. With time and experience, and refinement of appointment times, the efficiency of a virtual clinic from the provider's perspective can be expected to approach that of an in-person clinic.

In Canada, the demand for specialized surgical health services for children exceeds provincial capacity, resulting in wait times for both consultation and the surgical procedure itself. Ambulatory care capacity is driven by a combination of surgeon availability, clinic space and staffing. In addition to providing a patient-centred alternative to travel to the specialty centre, telehealth provides additional ambulatory care capacity by providing an alternative route of access to care, effectively diverting some of the traditional 
hospital-based clinic volume. In this way, telehealth can be viewed as a benefit not only to patients who use it but also to the health care system as a whole, provided that a commitment to telehealth does not significantly reduce provider availability to staff the ambulatory clinic.

During the 3-year time frame of our study, in which 80 patients were seen via telehealth, more than 7000 patients were seen in the pediatric surgery clinic, of whom about 1400 (20\%) would have met "remoteness" criteria for a telehealth appointment. Over the course of the study period, provider experience and confidence increased, so that now we would consider most follow-up consultations and at least half of new referrals to be eligible for a telehealth assessment. The main reason to exclude a patient for virtual assessment would be an assumption that a "hands-on" physical examination would be critical to patient evaluation, such as might be the case if the referral was for abdominal pain or an abdominal mass, or if it was certain that the patient required a diagnostic test or imaging study not available locally.

An additional objective of our study was to see whether adoption of a pediatric surgery telehealth program would lead to a reduction in Wait 1 within the pediatric surgery practice at BC Children's Hospital. Given the small proportion of telehealth visits overall, no difference in Wait 1 could be shown over the course of the study; however, it is possible that, with increased overall use, a telehealth program could be shown to reduce overall wait times for consultation.

Consideration should also be given to the important issues of privacy protection and regulation. It is the telehealth provider's responsibility to ensure that both the physician site and the remote site are using technology that complies with privacy/security and accreditation standards. The provider is obliged to acknowledge to the patient the limitation of technology-based consultation and to exercise caution when making treatment decisions or prescribing medication for patients whom they have not personally examined. Finally, the provider must maintain confidential records and communicate with the referring or other treating physician, as would be required for any in-person consultation.

\section{Limitations}

This study clearly has limitations. It represents a single surgeon's experience with relatively small numbers, and one should not assume that the results are generalizable to other children's surgical specialties. This is particularly true from the perspective of the amenability of new referrals to virtual assessment in other specialties, as well as any assumptions made about provider satisfaction. Nevertheless, the findings suggest that there are clear benefits from the family's perspective, which should be relevant regardless of surgical specialty.

\section{Conclusion}

Our findings suggest that virtual care provided through a pediatric surgical telehealth clinic has high value for families from remote communities in terms of encounter quality and travel cost avoidance. Virtual pediatric surgical care is an effective complement to in-person ambulatory care from the provider perspective, and it maximizes capacity of hospital-based clinics for those who require access to it. The role of telehealth in delivery of health care services is likely to increase as enabling information and communication technology becomes more widely adopted. Given the demands for access to subspecialty children's surgical consultation, investment in infrastructure to support telehealth benefits families who are geographically remote from the referral centre. This technology also has the potential to benefit delivery of children's surgical services overall by increasing system capacity. Pediatric surgeons should be open to the possibility of providing telehealth consultation but must be attentive to its limitations.

Affiliations: From the Department of Surgery, University of British Columbia, Vancouver, BC (Dean, Skarsgard); the Department of Pediatrics, University of British Columbia, Vancouver, BC (O'Donnell); the Office of Pediatric Surgical Evaluation and Innovation, Department of Surgery, BC Children's Hospital (Zhou); and the BC Children's Hospital, Child Health BC, Vancouver, British Columbia (O’Donnell).

Funding: This work was partially funded by the BC Patient Safety \& Quality Council. Child Health BC provided infrastructure and program support for telehealth services.

Competing interests: None declared.

Contributors: P. Dean, M. O'Donnell and E. Skarsgard designed the study. P. Dean, L. Zhou and E. Skarsgard acquired the data, which all authors analyzed. P. Dean and E. Skarsgard wrote the article, which all authors reviewed and approved for publication.

\section{References}

1. Ryu S, Yoo S, Lee KH, et al. Telemedicine: opportunities and developments in Member States. Report on the second global survey on eHealth. Vol 2 of Global observatory for eHealth series. Geneva: World Health Organization; 2010.

2. Strehle EM, Shabde N. One hundred years of telemedicine: Does this new technology have a place in paediatrics? Arch Dis Child 2006; 91:956-9.

3. The atlas of Canada. 6th ed. Ottawa: Natural Resources Canada; 2001. Available: www.atlas.gc.ca (accessed 2016 July 19).

4. Humer ML, Luoma A, Nelems B. Distant thoracic surgical patient assessment in rural British Columbia 1985-2005. BCM7 2006;48: 279-84.

5. Grzybowski SC, Cadesky AS, Hogg WE. Rural obstetrics: a 5-year prospective study of the outcomes of all pregnancies in a remote northern community. CMA7 1991;144:987-94.

6. Miles JE. A psychiatric outreach project to a rural community. Hosp Community Psychiatry 1980;31:822-5.

7. Miller GG, Levesque K. Telehealth provides effective pediatric surgery care to remote locations. F Pediatr Surg 2002;37:752-4.

8. Bator EX, Gleason JM, Lorenzo AJ, et al. The burden of attending a pediatric surgical clinic and family preferences toward telemedicine. F Pediatr Surg 2015;50:1776-82. 